\title{
A Study of Students' English Cooperative Learning Strategy in the Multimedia Environment
}

\author{
Ling Wang \\ School of Foreign Languages, Nanchang Normal University, Nanchang, China
}

\begin{abstract}
As a new learning mode, cooperative learning is of great significance to the students' learning and development. In our country it has achieved remarkable results, and its implementation of a wide range, especially in the field of English teaching has made great achievements. This essay starts with the background and development of cooperative learning. From the characteristics of the multimedia environment, we make a comprehensive discussion of how to use effective means, multimedia network environment and the multimedia tools, to promote students' English cooperative learning. Multimedia environment in the application of cooperative learning has produced some magical effects. Students can search for English language learning materials, and the study model can help students to establish a cooperative team to start learning together. At the same time, the teachers assist to guide, and ultimately achieve better results than the traditional teaching.
\end{abstract}

Index Terms - multimedia network environment, cooperative learning, the usage of the multimedia in schools

\section{INTRODUCTION}

Promoting the education modernization by informatization, achieving the leap forward development of education, speeding up the integration of information technology and curriculum have become the important ways for education reform and development. Network is an important symbol of the information society, which has tens of thousands of information, resource sharing, friendly interface and increasingly attracted the attention of education sectors (Wang.2015) .Multimedia network teaching has gradually entered the classroom, which has become a new bright spot in class. In the field of education, multimedia network education centers on the computer, and puts the word image processing technology and audio-visual technology together. And through the audio, video signal analog-to-digital conversion and data compression, learners can study autonomously and cooperatively, which can help to strengthen learning and improve the understanding of learning content. We can use interactive network, virtual space, sharing in real time, the characteristics of various forms to stimulate students' interest and enthusiasm in learning, through the establishment of interactive platform, network English corner, the wrong set of questions, the database way, and so on. And then let students get self-study purposes under the guidance of interest.

Cooperative learning is a teaching activity based on the cooperative learning group, and it is a learning method that students through interactive, complementary, mutual aid and cooperation together to reach the learning objectives. (Slavin.1987) What's more, Cooperative learning is a kind of new learning style, which is actively promoted by the new curriculum standard. And it is not only the important characteristic of the modern education, but also one of the important goals of curriculum reform and development in China. The newly implemented standard, named English Curriculum Standards, advocates to take the use of activities. The newly implemented standards let students take part in learning activity through the way of autonomous learning, cooperative learning and inquiry learning. What's more, it emphasizes the change of the learning style. In our country, with the continuous deepening of the basic education reform, the teaching application named cooperative Learning is more and more used extensively in high school English.

\section{THE Characteristics OF High SCHOOL StUdents}

The students have different characteristics in the different growth stages, and all aspects are more or less in the stage of changing. When we are carrying out the education, first of all, it is important to understand the characteristics of the physical and the mental development of students. It is true that only by following the characteristics of students' physical and mental development and the law of education, can we get a good education.

\section{A. The Psychological Characteristics}

Senior high school students' mental health problems are mainly subject to the changeable moods, low self-control, low psychological endurance and the lack of self-confidence. What's more, learning difficultly, test anxiety, inattention, unsteady learning achievement are also causing their mental health problems.

However, the new curriculum standard advocated learning form, which is named cooperative learning adapts to the psychological characteristics of high school students. Different stages of high school students have different levels of thinking. The level of abstract thinking of high school students has entered a critical period from the experience oriented theory to the dominant transition. During the development of abstract thinking rate reached the highest point in history, other indicators have learning ability and not much difference from adults. However, a part of the students after entering 
high school, comparing to the junior high school the corresponding increase in their studies, and they feel the pressure of learning and have a sense of urgency. Another part of the students think they bid farewell to the junior high school, and finally they can be free and can be appropriate to relax. Therefore, this kind of psychology will lead to uneven performance.

After a year of adaptation and learning, the high school students, who are studying in Grade Two are more obvious in the the extent of the knowledge level. Their thinking ability is further improved, and the ability of dialectical logical thinking will also be further developed. For the high school students, studying in Grade Two with excellent academic performance, their positive and confident psychology will continue to be enhanced, and learning interest is increasing for fun. What's more, learning has become a conscious act. However, on the contrary, another part of the students during the process of study in this year often encountered the setbacks. in the end, it causes the feeling of upset and lets students lose the interesting in learning. What's more, inferiority, timid, afraid and some other psychology problems will be solidified gradually.

The psychological characteristics of Grade Three senior high school students are more special, which can be divided into three periods. The three periods are psychological pressure period, relieve psychological pressure period and excitation sprint period. In everyone's mind, they think the Grade Three in senior high school is more critical. Become or lost in this year, so the psychological pressure of students in this period will be greater. As a matter of fact, these pressures are not only from their own heart, but also from the teachers' and parents' expectations of their own. For a student, the third year in senior high school is not only meant to sweat and tears, but also means a lots of suffering from the heart. In the same time, teachers and parents are not easy, they have to know about the students' characteristics of the psychological changes, help ease the psychological pressure of students, give support to the students, and help students achieve their own goals in life.

\section{B. The Learning Characteristics}

New curriculum standard advocated learning form, cooperative learning, not only adapt to the psychological characteristics of high school students, but also the same to adapt to the learning characteristics of high school students. There are four main characteristics of high school learning, which are the abstraction of the concept, the logic of the argument, the flexibility of the method and the application of a wide range. High school teaching material is different from the junior high school teaching material. It has entered a higher level in learning, and it requires in-depth understanding of quantitative research. And the teaching material of the abstract and general are greatly strengthened. What's more, high school learning more focus on observation ability, thinking ability, imagination, attention ability, creative ability, analysis problem, solve the problem and the operation ability of the training. Also, it pays more attention to the application of knowledge.

The characteristic of senior high school students' English learning method is also has flexibility. Now English learning is also very emphasis on the training of listening ability. The students not only have listening training and testing in the normal classroom, but also have the listening test section in the test. So it is very important of the usual listening training. There is an old saying, "Be aware of everything." As a matter of fact, There are a lot of ways to train your listening skills in your life. In school, the teacher can use the school multimedia, for example, the tape recorder, computer and so on in the classroom listening and text articles, helping students to train the ability of listening. In daily life, there are some small ways, both in the spirit of entertainment to relax themselves, but also help themselves to catch the purpose of mastering the knowledge, improving the ability of English listening. For example, The students are able to reach the goal of English Listening Training through watching the small drama, plays and films at the English pronunciation, listening to the voice of America, BBC broadcasting and so on. So it can be seen that there are many ways to learn English, and the flexibility of learning English is very strong.

\section{The COOPERATION LEARNING UNDER THE MULTIMEDIA ENVIRONMENT}

In the multimedia network environment, the teaching view emphasizes the students' active learning. However, the traditional teaching view advocates develop the leading role of teachers, which exaggerate arbitrarily the leading role of teachers. Through the study of high school students' English cooperative learning strategy under the multimedia environment, we can get easily that it provides students with diverse learning ways to learn English, and can also improve students' learning efficiency.

\section{A. The Characteristics of the Multimedia Environment}

In today's world science and technology have been developing and innovating continuously. On the one hand, it is closely related to the fate of the country, which determines the status of a country in the world. On the other hand, it is closely related to people's daily life. Similarly, in the process of learning knowledge, you can also use the mysterious force of science and technology in the school. It not only makes the students' study life both rich and interesting, but also improve the quality of teaching. There are three characteristics of multimedia network environment. First of all, the teaching content forms are various. Secondly, the teaching resources are shared. And then, the teaching information is comprehensive.

The form of multimedia teaching content is varied. A good lesson is not only related to the teacher's knowledge level, 
but also related to design a good classroom teaching steps and links. So this can make use of multimedia to enrich the content of classroom teaching. How does multimedia play its positive role? Multimedia assisted instruction set sound, image and animation in one. It is more rich and simultaneous. So the use of it can provide students with a variety of forms, functions of different perceptual materials, vivid image of the knowledge. For example, when the teacher begins to teach a new lesson, you can first use PPT to present the knowledge involved in the introduction. The forms are varied, and it can be animated, and can also be audio and video, too. When teaching the text, you can also use the audio player to help students learn the text. It is obvious that these forms of teaching are different from the traditional form, a single form of teaching. The teacher can combine teaching content with multimedia, and also promote the interaction between teachers and students. In a word, multimedia assisted instruction makes the classroom rich and active, but also can achieve a good teaching effect.(Liu.2014)

Another feature of multimedia teaching is the sharing of resources. Network transmission of information is very fast, and it can be quickly transmitted to the network to connect users with the information needed, high efficiency. What's more, network resources also have the characteristics of openness, and any online users or users can find the information they need on the Internet. These two characteristics of the network to ensure the sharing of network resources. Therefore, in the process of using multimedia assisted teaching, teaching resources also have the characteristics of sharing. In the classroom, when the teacher are talking about the knowledge related to the knowledge outside the textbook, they can query the Internet or by questioning the classroom multimedia computer, which can quickly and accurately find the required knowledge, and then use the big screen show, letting the students study by watching the screen. This not only can mobilize the classroom atmosphere, letting the learning be more interesting in the classroom, but also can help students learn a lot of useful and interesting knowledge. So the sharing of resources is a very obvious feature of multimedia teaching.

Multimedia network environment also has the characteristics of the integrated teaching information. In the same time, the sharing of multimedia teaching resources to a certain extent also promotes the integration of teaching information. The sharing of network resources provides people with rich information, and various courses and all kinds of knowledge are well presented, and even the relevance of these disciplines is also a good summary of the information, so that the teaching of information has the characteristics of a comprehensive. Multimedia computer system integrates all kinds of information, focusing on the processing and finishing, and then make a comprehensive performance. This improves the information acquisition, processing, storage, and expression of the method. And it enables students to obtain information through the organic combination of a variety of senses, so that it can attract more attention of students and so on.

The teachers are in the dominant position in the traditional teaching mode, and the knowledge is mainly based on the way of infusion. However, multimedia network assisted instruction is superior to the traditional teaching. It use the Multimedia in the teacher's teaching process, which will achieve a very good teaching expected results

\section{B. The Usage of the Multimedia in Schools}

In today's society, the state pays great attention to the development of politics and economy, and politics and economy also affect the development of culture. At the same time, the state also pays great attention to the development of culture and education. Education sector goes on reforming, improving the educational measures in order to enhance the quality of education. The role of multimedia in daily teaching is becoming more and more obvious, which is more and more popular with teachers and students. Now in addition to some poor mountain or rural school, the education equipment is not complete, and education facilities are relatively backward, other areas of primary and secondary schools in the application of multimedia is still relatively wide. Among them, the modern information technology represented by the computer plays an important role, so the teacher uses the computer to make the courseware and to use the multimedia courseware in the classroom. Compared to schools in the city or in the rich area, the educational facilities in these schools are more advanced and better. The students can watch and learn the relevant knowledge of the American film and play in the classroom. Some schools even at each seat set up the headset. In the training of English listening, this is very convenient. When students read articles or listening content, they can also use the advanced equipment to pass their reading through the microphone and the ear wheat to the teacher and the other students. Then reaching the interactive learning effect. So in the relatively developed areas of the economy, the amount of multimedia equipment is so much and the quality is relatively good.

However, in some economically backward rural or remote and poor mountainous areas, there is a shortage of teaching resources in the school. Not to mention the use of multimedia equipment, the use of the number of the multimedia is zero. They still adopt the traditional teaching mode in the class. Teacher's teaching still occupies the leading position in the teaching process. And some schools are affected by various factors, multimedia design is not enough, and it can not meet the actual needs of teaching.

\section{The Evaluation of COOPERATIOn LEARning Under the Multimedia ENVIRONMENT}

The high school students' English Cooperative Learning strategy in the multimedia network environment has adapted to the development needs of the students. And it also promotes the development of the education. Although everything has two sides, but the advantages of this learning model is much greater than the deficiencies. So this kind of teaching 
mode will be very effective, and in the future it will have a very good development prospects.

\section{A. The Advantage of Learning Model under the Multimedia Environment}

Through the research of the senior high school students' English Cooperative Learning under the multimedia network environment, it is found that it has many advantages. Firstly, the application of multimedia technology in English teaching not only conforms to the law of language acquisition, but also can improve the students' learning efficiency. The interaction and communication between teachers and students, or between students, and the use of multimedia in the teaching process all mobilize the learning atmosphere. In the good learning process, students' attention will be more concentrated, and the final learning efficiency will be improved. Secondly, multimedia network technology can also simulate the thinking world, reproduce the process of thinking to promote students thinking, divergent thinking, cultivate their spatial imagination and creativity. Thirdly, it also gives the teacher some advice that guide the high school students how to study effectively.(Patesan.2016) In the traditional teaching environment, the teaching mode is single, and in the class the teacher's teaching is the main. There is no other reference, so if the teacher is wrong, it will be rarely found. But in the process of teaching the use of cooperative learning and the use of multimedia technology and equipment, it will improve the shortcomings of traditional teaching. During the cooperative learning between teachers and students, or students themselves, the teacher can communicate with the learner, so that they can understand the student's thinking and inner thoughts. Then the teacher can find a more appropriate teaching, counseling programs and so on after the collision of ideas and inner thought between them and the students. What's more, the teacher can search the information on the computer, then combining with the quality of online courseware form their own unique teaching mode and teaching methods.

\section{B. The Deficiency of High Schools' English Cooperative Learning}

With the developing direction of the basic education curriculum reform, the new learning style of cooperative learning also has a new development, too. In English teaching, it not only improves the learning efficiency, promotes the students' feelings, raises the students' ability of organization, but also broadens the students' learning space. It changes the one-way or two-way communication between teachers and students in traditional teaching. And it extends the students' learning to the outside class. The more important is to reflect the students' subject status. Through the cooperative learning group, the members ask questions or elaborate on their views and opinions, letting students play a positive role by themselves.

However, as the old thing goes that everything has two sides. There are still some problems in English Cooperative Learning Strategies for senior high school students. Some students may be ignored so that the learning model has to always change the form of its activities and increase the power of the new. (Ye.2012) What's more, the teachers may ignore their responsibilities.

First of all, in the learning process, cooperative learning may ignore some students, who have a sense of inferiority or whose academic performance is unsatisfactory. Cooperative learning reflects the main status of students, encouraging students to be brave in class, and actively show their own. But there is a fact that often speaking or expressing their own inner views and opinions are those who are outstanding, cheerful and optimistic. However, students who are not ideal or have an inferiority complex will suffer more psychological pressure (Cui.2011). When they are in the face of such a positive and exciting students, who answer questions and take part in the class activities actively, they don't know what to do, and they will have bad a feeling that his or her answer is not perfect or not correct. They even more inferiority, not to participate in the classroom activities with excellent students, but more of their own to hide in the corner, isolating themselves, thus learning to a less optimistic situation that the better is best and the poor is worse. The gap between students will be bigger and bigger.

Then this cooperative learning model needs to fill the energy and increase the novelty from time to time. At the beginning of cooperative learning, most students feel fresh, fun and interesting, and they are more active to take part in the activities. (Lin.2014)But this kind of cooperative learning is difficult to maintain for a long time, because it depends on the shallow level of interest to participate in. In the process of group cooperative learning, all students must not only learn to gain the knowledge but also gain more. And let the students have a sense of success in the end. Only this deep level of interest can make the group cooperative learning activities be maintained for a long time. Therefore, the group cooperative learning activities can not have only one form. It should not only be diversified, which is the variety of activities, space, time, content and manner of conversion, but also closely organize the team members to actively participate in effective learning activities. It make the team members really have a warm and enthusiastic heart, and then let them achieve the purpose of interaction, complementary, common progress and development purposes

What's more, the teacher may don't pay much attention to their duties in the teaching process. While cooperative learning requires students to improve the main position in the learning process, but the teacher can not have the sense of negative and lazy. They should have an accurate position in the the teaching process, and the teacher's responsibility can not be lost. Teachers should still have a deep understanding of the development characteristics of the students' physical and mental, and guide students to learn the knowledge. When students are study cooperatively, teachers still have to carefully observe the students' performance, make the correct judgment of the students' answers, and point out their mistakes. 


\section{The Future Development of the Cooperation Learning under the Multimedia Environment}

Since there are so many advantages of cooperative learning in the multimedia network environment, with the continuous progress and development of the society, the senior high school students' cooperative learning strategies under the multimedia network environment will have a further applied. And it will have a very good future.

The Ministry of education will still actively promote the new learning model of cooperative learning, and enhance the quality and level of education with the help of multimedia technology. The relevant government departments will even give funding to the poor and backward areas, distribute educational resources, improve their educational equipment, comprehensively improving the education, and then improve the overall level of the education. Everything in the world is in constant motion. Therefore, I believe that this kind of advanced teaching form can be continuously improved and optimized, and its problems and deficiencies will be improved accordingly. For example, not only to strengthen the input of educational resources, improve educational facilities, but also to improve the standards of teachers and to strengthen the training of teachers. Including the influence of the thought and the training of multimedia operation technology, it is making the teachers in the teaching process to form their own unique teaching mode.

Each school responds to the call of the Ministry of education on the reform of basic education curriculum, and then strengthen the improvement and investment of educational equipment. Colleagues also focus on the selection of teachers, thickening of teachers, and they run a number of training for the team of teachers actively. The key is to improve teachers' ideological consciousness through training, so they can't make themselves lazy. The teacher should make use of the strength of the multimedia teaching equipment, making the teaching effect to reach the highest level. Eventually an organized and distinctive teacher team will be made up. For teachers, they will study further consciously, improving their self-cultivation and ideological awareness. They will form their own innovation spirit, break through the traditional teaching form, and increase its novelty.

\section{REFERENCES}

[1] Jingjing. Cui. (2011). Research on High School Students' English Learning Anxiety. Journal of Language Teaching \& Research. (4): 2011(4): 875-880.

[2] Marioara Patesan. (2016). The Benefits of Cooperative learning. International Conference Knowledge-based Organization. De Gruyter. 2016(2): 478-483.

[3] Meixiao. Lin. (2014). Effects of Cooperative Learning on Interactional Strategy Use in EFL Context: An Analysis of Chinese Students' Classroom Talks. International Conference Knowledge-based Organization. De Gruyter. 2014(1): 49-66.

[4] Qian Wang. (2015). A Study of the Influence of Gender Differences on English Learning of Senior High School Students. CSCanada. 2015, (6): 66-69.

[5] Robert E Slavin. (1987). Research on Cooperative Learning: an International perspective. Scandinavian Journal of Educational Research. 1987(4): 12-13.

[6] Xiaoxiao. Ye. (2012). Students' English Anxiety in Senior High School. Overseas English. 2012(8): 59-63.

[7] Yu. Liu (2014). The Ways to Motivate the Senior High School Students to Learn English. Overseas English. 2014. (2): 16-17.

Ling Wang was born in Jian, China in1967. She received her bachelor of Art degree in linguistics from Jiangxi Normal University, China in 1995.

She is currently an associate professor in the School of Foreign Languages, Nanchang Normal University, Nanchang, China. Her research interests include cross-cultural teaching and teaching methods.

Prof. Wang is a member of the Chinese Association of Foreign Language Teacher. 